\title{
SIFAT-SIFAT DASAR INTEGRAL HENSTOCK
}

(Basic Properties of Henstock Integral)

\author{
LEXY JANZEN SINAY, MOZART WINSTON TALAKUA \\ Staf Jurusan Matematika FMIPA UNPATTI \\ Jl. Ir. M. Putuhena, Kampus Unpatti, Poka-Ambon \\ e-mail: lexyjz@gmail.com
}

\begin{abstract}
This paper was a review about theory of Henstock integral. Riemann gave a definition of integral based on the sum of the partitions in Integration area (interval $[a, b]$ ). Those partitions is a $\delta$-positive constant. Independently, Henstock and Kurzweil replaces $\delta$ positive constant on construction Riemann integral into a positive function, ie $\delta(x)>0$ for every $x \in[a, b]$. This function is a partition in interval $[a, b]$. From this partitions, we can defined a new integral called Henstock integral. Henstock integral is referred to as a complete Riemann integral, because the basic properties of the Henstock integral is more constructive than Riemann Integral.
\end{abstract}

Keywords: Henstock Integral, Partitions, Riemann Integral, $\delta$-Positive Constant

\section{PENDAHULUAN}

Sekitar tahun 1670, Kalkulus berhasil ditemukan, dan tokoh-tokoh matematika yang berperan dalam penemuan Kalkulus adalah Newton dan Leibniz. Kedua tokoh ini berhasil mengembangkan Teorema Fundamental, yaitu mengenai antiderivatif. Kemudian A. Cauchy (1789-1857) mulai mengembangkan teori tersebut, dan berhasil meneliti tentang integral dari fungsi kontinu.

Pada tahun 1854, Bernhard Riemann mulai memperhalus definisi yang digunakan oleh Cauchy, dan Riemann pun mengadakan penelitian tentang integral fungsi diskontinu. Riemann berhasil menemukan suatu metode khusus dari integral yang sangat simpel untuk didefinisikan, sehingga metode integral itu disebut integral Riemann.

Kemudian pada tahun 1875 Darboux berhasil memodifikasi integral Riemann dengan mendefinisikan integral atas dan integral bawah sehingga terdefinisi suatu integral baru yang ekuivalen dengan integral Riemann. Teori integral yang dikemukakan oleh Darboux masih memiliki kekurangan.

Pada tahun 1902 Henry Lebesgue (1875-1974) menemukan suatu pendekatan baru untuk integrasi, yang mana metode tersebut mengatasi kekurangan-kekurangan yang dimiliki oleh integral-integral sebelumnya, terutama mengatasi kekurangan pada integral Riemann. Metode integral tersebut sering disebut integral Lebesgue.

Kemudian, secara terpisah ada beberapa tokoh yang melakukuan penelitian tentang teori integral (terutama integral Riemann) dan berhasil mendefinisikan teori-teori integral yang lebih konstruktif. Tokoh-tokoh tersebut adalah Arnaud Denjoy (1912), Oscar Perron (1914), Ralph Henstock dan Jaroslav Kurzweil pada dekade 1950-1960. Secara mendasar, metode integral yang ditemukan oleh para tokoh-tokoh tersebut ekuivalen, namun integral Henstock (Henstock-Kurzweil) lebih unggul dibandingkan integral Denjoy-Perron.

Berdasarkan hal ini maka penulis sangat tertarik dan menganggap perlu untuk mengulas kembali tentang definisi dari integral Henstock dan sifat-sifat dasar integral yang berlaku pada integral Henstock.

\section{TINJAUAN PUSTAKA}

Dekade 1950-1960, masing-masing secara terpisah (independen) yaitu Henstock dan Kurzweil mendefinisikan integral baru. Teori integral tersebut merupakan generalisasi dari integral Riemann dengan mengubah konstruksi $\delta$ pada integral Riemann, sehingga dibentuk suatu partisi yang baru pada daerah pengintegralannya. Dengan demikian formula tersebut lebih konstruktif (Thobirin, 1997). Teori integral tersebut 
juga lebih mudah dari integral Denjoy maupun integral Peron. Pada umumnya, teori tersebut disebut integral Henstock-Kurzweil yang sering juga disebut integral Henstock sangat mudah dibandingkan integral Lebesgue dan definisinya agak berbeda dari integral Riemann. (Schechter, 2001).

Berikut ini akan diberikan beberapa pengertian dan sifat yang akan digunakan dalam pembahasan.

Teorema 1 (Teorema Heine-Borel) [Royden (1987)] Jika $\wp$ liput terbuka suatu himpunan tertutup dan terbatas $F$ dalam $\overline{\mathbb{R}}$, sedemikian sehingga $F \subset \cup\{O: O \in \wp\}$ maka terdapat liput terbuka bagian berhingga untuk $F$.

\section{Integral Riemann}

Jika $a$ dan $b$ adalah bilangan riil dengan $a<b$ maka terdapat bilangan riil $x_{1}$ sehingga $a<x_{1}<b$. Karena $x_{1}<b$ tentu terdapat bilangan riil $x_{2}$ sehingga memenuhi $x_{1}<x_{2}<b$. Karena $x_{2}<b$ maka terdapat bilangan riil $x_{3}$ sehingga memenuhi $x_{2}<x_{3}<b$. Proses ini jika diteruskan akan diperoleh bilangan-bilangan $x_{1}, x_{2}, x_{3}, \ldots x_{n}$ sehingga

$$
a=x_{0}<x_{1}<x_{2}<\ldots<x_{n}=b
$$

Jadi untuk setiap interval tertutup $[a, b]$ dapat dibentuk himpunan

$$
\begin{gathered}
D=\left\{a=x_{0}, x_{1}, x_{2}, \ldots, x_{n}=b\right\} \\
\text { dengan } a=x_{0}<x_{1}<x_{2}<\ldots<x_{n}=b
\end{gathered}
$$

Sehingga dapat dibentuk definisi partisi Riemann seperti di bawah ini.

\section{Definisi 2}

a). Untuk setiap bilangan riil $a$ dan $b$ dengan $a<b$ himpunan terurut

$$
D=\left\{a=x_{0}, x_{1}, x_{2}, \ldots, x_{n}=b ; \xi_{1}, \xi_{2}, \ldots, \xi_{n}\right\}
$$

dengan

$$
a=x_{0}<x_{1}<x_{2}<\ldots<x_{n}=b \text { dan } \xi_{i} \in\left[x_{i-1}, x_{i}\right]
$$

disebut partisi Riemann pada $[a, b]$

Titik $x_{i}$ dengan $i=0,1,2, \ldots, n$ pada $D$ disebut titik partisi (partition point) dan $\xi_{i} \in\left[x_{i-1}, x_{i}\right]$ disebut titik tag (tag point).

b). Norma $D$, dinotasikan dengan $\|D\|$ adalah bilangan $\operatorname{maks}\left\{x_{i}-x_{i-1} ; i=1,2, \ldots, n\right\}$

c). Suatu partisi Riemann $D_{1}$ pada $[a, b]$ disebut penghalus partisi Riemann $D_{2}$ pada $[a, b]$ jika $D_{2} \subset D_{1}$, artinya setiap titik partisi dalam $D_{2}$ termuat juga di dalam $D_{1}\left(D_{2}\right.$ lebih halus dari $\left.D_{1}\right)$.

Dengan adanya partisi pada $[a, b]$ (partisi Riemann) maka didefinisikan integral Riemann seperti berikut ini.

\section{Definisi 3 (Integral Riemann)}

Suatu fungsi $f:[a, b] \rightarrow \mathbb{R}$ dikatakan terintegral Riemann jika ada bilangan $A$ sehingga untuk setiap $\varepsilon>0$ terdapat $\delta$ $>0$ sehingga jika

$$
D=\left\{a=x_{0}, x_{1}, x_{2}, \ldots, x_{n}=b ; \xi_{1}, \xi_{2}, \ldots, \xi_{n}\right\}
$$

Partisi Riemann pada $[a, b]$ dengan $\|D\|<\delta$ berlaku

$$
\left|(D) \sum_{i=1}^{n} f\left(\xi_{i}\right)\left(x_{i}-x_{i-1}\right)-A\right|<\varepsilon .
$$

Selanjutnya bilangan $A$ disebut nilai integral Riemann fungsi $f$ pada $[a, b]$ dan dinotasikan dengan

$$
A=(R) \int_{a}^{b} f(x) d x
$$

\section{HASIL DAN PEMBAHASAN}

Bagian ini akan dibahas mengenai integral Henstock yang sering pula disebut integral Riemann Lengkap (Complete Riemann Integral) beserta sifat-sifatnya.

\section{Integral Henstock}

Sebelum diuraikan mengenai integral Henstock terlebih dahulu dibahas tentang partisi. Karena integral Henstock didasarkan atas adanya partisi pada daerah pengintegralannya. Partisi tersebut adalah partisi- $\delta$ yang dapat dilihat pada definisi berikut ini.

\section{Definisi 4}

Diketahui fungsi positif $\delta:[a, b] \rightarrow \overline{\mathbb{R}}$. Diberikan sebuah partisi $D=\left\{a=x_{0}, x_{1}, \ldots, x_{n}=b ; \xi_{1}, \xi_{2}, \ldots, \xi_{n}\right\}$ pada $[a, b]$ yang memenuhi

$$
\xi_{i}-\delta\left(\xi_{i}\right)<x_{i-1} \leq \xi_{i} \leq x_{i}<\xi_{i}+\delta\left(\xi_{i}\right),
$$

untuk setiap $i=1,2, \ldots, n$ dinamakan partisi- $\delta$

( $\delta$-partition atau $\delta$-fine partition) pada $[a, b]$.

Lebih singkat, partisi $D$ dapat ditulis $\{[u, v] ; \xi\}$.

Karena integral yang akan didefinisikan berkaitan dengan pengertian partisi- $\delta$, maka akan diperlihatkan tentang eksistensi dari partisi- $\delta$ tersebut pada sebuah selang tertutup $[a, b]$.

\section{Teorema 5}

Untuk setiap fungsi positif $\delta:[a, b] \rightarrow \mathbb{R}$ terdapat suatu partisi- $\delta$ pada $[a, b]$.

\section{Bukti}

Misalkan $\delta:[a, b] \rightarrow \mathbb{R}$ fungsi positif.

Untuk setiap $\xi \in[a, b], \delta(\xi)>0$ sehingga dapat dibentuk liput $(u, v)$ yang memenuhi

$$
\xi-\delta(\xi)<u<\xi<v<\xi+\delta(\xi)
$$

yaitu $I_{\xi}$, sehingga dapat dibuat keluarga $\mathfrak{I}_{\xi}=\left\{I_{\xi}\right\}$.

$$
\sigma=\left\{I_{\xi} \mid I_{\xi} \in \mathfrak{J}_{\xi}, \xi \in[a, b]\right\}
$$

merupakan liput terbuka dari $[a, b]$, yaitu 


$$
[a, b] \subset \bigcup_{I_{\xi} \in \sigma} I_{\xi} .
$$

Menurut Teorema 1 (Teorema Heine-Borel) terdapat liput terbuka bagian berhingga yaitu

$$
\left\{I_{\xi_{1}}, I_{\xi_{2}}, \ldots, I_{\xi_{n}}\right\} \subset \sigma \text { sehingga }[a, b] \subset \bigcup_{j=1}^{n} I_{\xi_{j}} .
$$

Ambil $a \leq \xi_{1}<\xi_{2}<\ldots<\xi_{n}=b$

Oleh karena $I_{\xi_{j-1}} \cap I_{\xi_{j}} \neq \varnothing$, sehingga dapat diambil $x_{j-1} \in I_{\xi_{j-1}} \cap I_{\xi_{j}}$ dengan $x_{j-1}=\frac{1}{2}\left(u_{j}+v_{j-1}\right), \quad j=2, \ldots, n$ dan ambil $x_{0}=a$ dan $x_{n}=b$.

dengan $x_{j-1}$ untuk setiap $j=2, \ldots, n$,

$$
u_{j-1}<\xi_{j-1}<x_{j-1}<\xi_{j}<v_{j}
$$

Jika diambil $x_{0}=a$ dan $x_{n}=b$ maka diperoleh:

dengan sifat

$$
a=x_{0}<x_{1}<\ldots<x_{n}=b
$$

$$
\xi_{j}-\delta\left(\xi_{j}\right)<x_{j-1} \leq \xi_{j} \leq x_{j}<\xi_{j}+\delta\left(\xi_{j}\right)
$$

Untuk setiap $j=1,2, \ldots, n$.

Jadi diperoleh

dengan sifat

$$
P=\left\{a=x_{0}, x_{1}, \ldots, x_{n}=b\right\}
$$

$$
\xi_{j}-\delta\left(\xi_{j}\right)<x_{j-1} \leq \xi_{j} \leq x_{j}<\xi_{j}+\delta\left(\xi_{j}\right)
$$

Berikut ini akan diperlihatkan sifat dari partisi- $\delta$ yang akan dipergunakan dalam pembahasan selanjutnya.

\section{Teorema 6}

Misalkan $\delta_{1}, \delta_{2}, \delta$ masing-masing merupakan fungsi bernilai riil positif pada $[a, b]$ dengan

$$
\delta(\xi)=\min \left\{\delta_{1}(\xi), \delta_{2}(\xi)\right\}, \xi \in[a, b]
$$

Jika $D$ partisi- $\delta$ pada $[a, b]$, maka $D$ juga merupakan partisi- $\delta_{1}$ dan partisi- $\delta_{2}$ pada $[a, b]$.

\section{Bukti}

Misalkan $D$ partisi- $\delta$ pada $[a, b]$ yang diberikan oleh $D=\left\{a=x_{0}, x_{1}, \ldots, x_{n}=b ; \xi_{1}, \xi_{2}, \ldots, \xi_{n}\right\}$

dengan $\xi_{i}-\delta\left(\xi_{i}\right)<x_{i-1} \leq \xi_{i} \leq x_{i}<\xi_{i}+\delta\left(\xi_{i}\right), i=1,2, \ldots, n$. Karena $\delta(\xi)=\min \left\{\delta_{1}(\xi), \delta_{2}(\xi)\right\}$

maka

$$
\delta(\xi) \leq \delta_{1}(\xi) \text { atau } \delta(\xi) \leq \delta_{2}(\xi) .
$$

Akibatnya

$\xi_{i}-\delta_{1}\left(\xi_{i}\right) \leq \xi_{i}-\delta\left(\xi_{i}\right)<x_{i-1} \leq \xi_{i}$

$$
\leq x_{i}<\xi_{i}+\delta\left(\xi_{i}\right) \leq \xi_{i}+\delta_{1}\left(\xi_{i}\right)
$$

dan juga

$$
\begin{aligned}
\xi_{i}-\delta_{2}\left(\xi_{i}\right) \leq \xi_{i}-\delta\left(\xi_{i}\right)<x_{i-1} & \leq \xi_{i} \\
& \leq x_{i}<\xi_{i}+\delta\left(\xi_{i}\right) \leq \xi_{i}+\delta_{2}\left(\xi_{i}\right)
\end{aligned}
$$

untuk $i=1,2, \ldots, n$.
Jadi $D$ merupakan partisi- $\delta_{1}$ dan partisi- $\delta_{2}$ pada $[a, b]$ dan terbukti pula bahwa $D$ partisi- $\delta$ lebih halus dari partisi- $\delta_{1}$ dan partisi- $\delta_{2}$.

Dengan menggunakan partisi- $\delta$ seperti didefinisikan pada Definisi 4, Henstock membangun integral Riemann Lengkap yang selanjutnya disebut integral Henstock, yang didefinisikan seperti berikut ini.

\section{Definisi 7}

Suatu fungsi $f:[a, b] \rightarrow \overline{\mathbb{R}}$ dikatakan terintegral Henstock jika ada bilangan $A$ sehingga untuk setiap $\varepsilon>0$ terdapat fungsi $\delta(\xi)>0$ pada $[a, b]$ sehingga untuk setiap partisi- $\delta$

$$
D=\left\{a=x_{0}, x_{1}, x_{2}, \ldots, x_{n}=b ; \xi_{1}, \xi_{2}, \ldots, \xi_{n}\right\}
$$

Pada $[a, b]$ berlaku

$$
\left|(D) \sum_{i=1}^{n} f\left(\xi_{i}\right)\left(x_{i}-x_{i-1}\right)-A\right|<\varepsilon
$$

$A$ disebut nilai integral Henstock fungsi $f$ pada selang $[a, b]$ dan dinotasikan dengan

$$
A=(H) \int_{a}^{b} f(x) d x
$$

$\operatorname{dan}(D) \sum_{i=1}^{n} f\left(\xi_{i}\right)\left(x_{i}-x_{i-1}\right)$ dinamakan jumlah Riemann yang bersesuaian dengan partisi- $\delta D$ pada selang $[a, b]$.

\section{Sifat-Sifat Integral Henstock}

Pada bagian ini akan dibahas beberapa sifat sederhana dari integral Henstock yang mana sifat-sifat tersebut merupakan sifat-sifat integral yang berlaku untuk integral Henstock.

Teorema 8 (Sifat ketunggalan integral Henstock) Jika fungsi $f:[a, b] \rightarrow \overline{\mathbb{R}}$ terintegral Henstock pada $[a, b]$, maka nilai integral itu tunggal.

\section{Bukti}

Diberikan $\varepsilon>0$ sebarang. Karena $f$ terintegral Henstock pada $[a, b]$ maka terdapat bilangan riil $A_{1}$ dan fungsi positif $\delta_{1}:[a, b] \rightarrow \mathbb{R}$ sehingga untuk setiap partisi- $\delta_{1}$ $D_{1}=\{[u, v] ; \xi\}$ pada $[a, b]$ berlaku

$$
\left|\left(D_{1}\right) \sum f(\xi)(v-u)-A_{1}\right|<\frac{\varepsilon}{2}
$$

Misalkan $f$ juga terintegral Henstock pada $[a, b]$ dengan nilai integral $A_{2}$, terdapat fungsi positif $\delta_{2}:[a, b] \rightarrow \mathbb{R}$ sehingga untuk setiap partisi- $\delta_{2} D_{2}=\{[u, v] ; \xi\}$ pada $[a, b]$ berlaku

$$
\left|\left(D_{2}\right) \sum f(\xi)(v-u)-A_{2}\right|<\frac{\varepsilon}{2}
$$


Didefinisikan fungsi positif $\delta:[a, b] \rightarrow \mathbb{R}$ dengan

$$
\delta(\xi)=\min \left\{\delta_{1}(\xi), \delta_{2}(\xi)\right\}, \xi \in[a, b]
$$

Menurut Teorema 6 , jika $D=\{[u, v] ; \xi\}$ partisi- $\delta$ pada $[a, b]$, maka $D$ juga merupakan partisi- $\delta_{1}$ dan partisi- $\delta_{2}$ pada $[a, b]$.

Sehingga diperoleh :

$$
\begin{aligned}
\left|A_{1}-A_{2}\right|= & \mid A_{1}-(D) \sum f(\xi)(v-u) \\
& +(D) \sum f(\xi)(v-u)-A_{2} \mid \\
\leq & \left|A_{1}-(D) \sum f(\xi)(v-u)\right| \\
& \quad+\left|(D) \sum f(\xi)(v-u)-A_{2}\right| \\
= & \left|(D) \sum f(\xi)(v-u)-A_{1}\right| \\
& \quad+\left|(D) \sum f(\xi)(v-u)-A_{2}\right| \\
< & \frac{\varepsilon}{2}+\frac{\varepsilon}{2}=\varepsilon
\end{aligned}
$$

Karena $\varepsilon>0$ diambil sebarang, maka terbukti $A_{1}=A_{2}$. Jadi nilai $A_{1}$ tunggal.

Seperti halnya integral Riemann, sifat kelinieran juga berlaku pada integral Henstock, dan sifat ini diungkapkan dengan teorema di bawah ini.

\section{Teorema 9}

Jika fungsi-fungsi $f$ dan $g$ masing-masing terintegral Henstock pada $[a, b]$ dengan demikian maka $f+g$ dan $\alpha f$ untuk $\alpha$ bilangan riil juga terintegral Henstock pada $[a, b]$ dan berlaku

(i). $(H) \int_{a}^{b}(f(x)+g(x)) d x=(H) \int_{a}^{b} f(x) d x$

$$
+(H) \int_{a}^{b} g(x) d x
$$

(ii). (H) $\int_{a}^{b} \alpha f(x) d x=\alpha(H) \int_{a}^{b} f(x) d x$

\section{Bukti}

Diberikan $\varepsilon>0$ sebarang.

(i). Misalkan

$$
(H) \int_{a}^{b} f(x) d x=A \operatorname{dan}(H) \int_{a}^{b} g(x) d x=B .
$$

Terdapat fungsi $\delta_{1}(\xi)>0$ pada $[a, b]$ sehingga untuk setiap partisi- $\delta_{1} D_{1}=\{[u, v] ; \xi\}$ pada $[a, b]$ berlaku

$$
\left|\left(D_{1}\right) \sum f(\xi)(v-u)-A\right|<\frac{\varepsilon}{2}
$$

dan juga terdapat fungsi $\delta_{2}(\xi)>0$ pada $[a, b]$ sehingga untuk setiap partisi- $\delta_{2} \quad D_{2}=\{[u, v] ; \xi\}$ pada $[a, b]$ berlaku

$$
\left|\left(D_{2}\right) \sum g(\xi)(v-u)-B\right|<\frac{\varepsilon}{2}
$$

Didefinisikan fungsi $\delta:[a, b] \rightarrow \mathbb{R}$ dengan

$$
\delta(\xi)=\min \left\{\delta_{1}(\xi), \delta_{2}(\xi)\right\}, \xi \in[a, b] .
$$

Berdasarkan Teorema 6 , jika $D=\{[u, v] ; \xi\}$ partisi$\delta$ pada $[a, b]$, maka $D$ juga merupakan partisi- $\delta_{1}$ dan partisi- $\delta_{2}$ pada $[a, b]$. Karena itu untuk sebarang partisi- $\delta$ pada selang $[a, b]$ berlaku

$\left|(D) \sum(f+g)(\xi)(v-u)-(A+B)\right|$

$=\left|(D) \sum(f(\xi)+g(\xi))(v-u)-(A+B)\right|$

$=\left|(D) \sum(f(\xi)(v-u)+g(\xi)(v-u))-A-B\right|$

$=\mid(D) \sum f(\xi)(v-u)$

$$
+(D) \sum g(\xi)(v-u)-A-B
$$

$=\mid(D) \sum f(\xi)(v-u)-A$

$$
\begin{array}{r}
+(D) \sum g(\xi)(v-u)-B \mid \\
\leq\left|(D) \sum f(\xi)(v-u)-A\right| \\
+\left|(D) \sum g(\xi)(v-u)-B\right|
\end{array}
$$

$<\frac{\varepsilon}{2}+\frac{\varepsilon}{2}=\varepsilon$

Sehingga $f+g$ terintegral Henstock pada $[a, b]$, ini berarti $f+g$ terintegral Henstock ke $A+B$ dengan

$$
\begin{aligned}
& (H) \int_{a}^{b}(f(x)+g(x)) d x=A+B \\
& =(H) \int_{a}^{b} f(x) d x+(H) \int_{a}^{b} g(x) d x
\end{aligned}
$$

(ii). Jika $\alpha=0$ maka jelas $\alpha f$ terintegral Henstock ke 0 . Untuk $\alpha \neq 0$.

Pilih fungsi $\delta_{3}(\xi)>0$ pada $[a, b]$,

sehingga untuk setiap partisi- $\delta_{3} \quad D_{3}=\{[u, v] ; \xi\}$ pada $[a, b]$ berlaku

$$
\left|\left(D_{3}\right) \sum f(\xi)(v-u)-A\right|<\frac{\varepsilon}{|\alpha|}
$$

Misalkan $D=\{[u, v] ; \xi\}$ sebarang partisi- $\delta_{3}$ pada $[a, b]$, maka

$$
\left|(D) \sum \alpha f(\xi)(v-u)-\alpha A\right|
$$




$$
\begin{aligned}
& =\left|\alpha\left((D) \sum f(\xi)(v-u)\right)-\alpha A\right| \\
& =\left|\alpha\left((D) \sum f(\xi)(v-u)-A\right)\right| \\
& =|\alpha|\left|(D) \sum f(\xi)(v-u)-A\right| \\
& <|\alpha| \cdot \frac{\varepsilon}{|\alpha|}=\varepsilon
\end{aligned}
$$

Sehingga

$\alpha f$ terintegral Henstock ke $\alpha A$ dengan

$$
(H) \int_{a}^{b} \alpha f(x) d x=\alpha A=\alpha(H) \int_{a}^{b} f(x) d x
$$

Lemma berikut ini adalah suatu kriteria untuk menyelidiki suatu fungsi terintegral Henstock tanpa mengetahui nilai integralnya. Kriteria ini sering disebut juga Kriteria Cauchy.

\section{Lemma 10}

Fungsi $f:[a, b] \rightarrow \overline{\mathbb{R}}$ terintegral Henstock pada $[a, b]$ jika dan hanya jika untuk setiap $\varepsilon>0$ terdapat fungsi $\delta(\xi)>0$ pada $[a, b]$ sehingga untuk sebarang partisi- $\delta$ $D=\{[u, v] ; \xi\}$ dan $D^{\prime}=\left\{\left[u^{\prime}, v^{\prime}\right] ; \xi^{\prime}\right\}$ pada $[a, b]$

berlaku

$$
\left|(D) \sum f(\xi)(v-u)-\left(D^{\prime}\right) \sum f\left(\xi^{\prime}\right)\left(v^{\prime}-u^{\prime}\right)\right|<\varepsilon
$$

\section{Bukti}

(i) Syarat cukup.

$f:[a, b] \rightarrow \overline{\mathbb{R}}$ terintegral Henstock pada $[a, b]$. Diberikan $\varepsilon>0$ sebarang. Terdapat $\delta:[a, b] \rightarrow \mathbb{R}$ sehingga untuk sebarang partisi- $\delta D=\{[u, v] ; \xi\}$ pada $[a, b]$ berlaku

$$
\left|(D) \sum f(\xi)(v-u)-A\right|<\frac{\varepsilon}{2}
$$

dengan $A=(H) \int_{a}^{b} f(x) d x$.

Jika $D=\{[u, v] ; \xi\}$ dan $D^{\prime}=\left\{\left[u^{\prime}, v^{\prime}\right] ; \xi^{\prime}\right\}$

partisi- $\delta$ pada $[a, b]$ berlaku juga

$$
\left|\left(D^{\prime}\right) \sum f\left(\xi^{\prime}\right)\left(v^{\prime}-u^{\prime}\right)-A\right|<\frac{\varepsilon}{2}
$$

maka

$$
\begin{aligned}
& \left|(D) \sum f(\xi)(v-u)-\left(D^{\prime}\right) \sum f\left(\xi^{\prime}\right)\left(v^{\prime}-u^{\prime}\right)\right| \\
& =\mid(D) \sum f(\xi)(v-u)-A \\
& \quad A-\left(D^{\prime}\right) \sum f\left(\xi^{\prime}\right)\left(v^{\prime}-u^{\prime}\right) \mid \\
& \leq\left|(D) \sum f(\xi)(v-u)-A\right|
\end{aligned}
$$

$$
\begin{aligned}
& \quad+\left|A-\left(D^{\prime}\right) \sum f\left(\xi^{\prime}\right)\left(v^{\prime}-u^{\prime}\right)\right| \\
& =\left|(D) \sum f(\xi)(v-u)-A\right| \\
& +\left|\left(D^{\prime}\right) \sum f\left(\xi^{\prime}\right)\left(v^{\prime}-u^{\prime}\right)-A\right| \\
& <\frac{\varepsilon}{2}+\frac{\varepsilon}{2}=\varepsilon
\end{aligned}
$$

(ii) Syarat perlu.

Misalkan $\left\{\varepsilon_{n}\right\}, \varepsilon_{n}>0$ untuk setiap $n \in \mathbb{N}$ adalah barisan monoton turun yang konvergen ke 0 $\left(\varepsilon_{n} \rightarrow 0\right)$.

Diketahui bahwa untuk setiap $\varepsilon_{n}$ terdapat $\delta_{n}$, $\delta_{n}(\xi)>0, \xi \in[a, b]$,

sehingga untuk setiap partisi- $\delta_{n}$

$D_{n}=\{[u, v] ; \xi\}$ dan $D_{n}^{\prime}=\left\{\left[u^{\prime}, v^{\prime}\right] ; \xi^{\prime}\right\}$ pada $[a, b]$ berlaku

$$
\begin{aligned}
& \mid\left(D_{n}\right) \sum f(\xi)(v-u) \\
& -\left(D_{n}^{\prime}\right) \sum f\left(\xi^{\prime}\right)\left(v^{\prime}-u^{\prime}\right) \mid<\varepsilon_{n}
\end{aligned}
$$

Definisikan $S_{n}=\left(D_{n}\right) \sum f(\xi)(v-u)$ untuk setiap $n \in \mathbb{N}$ dibentuk barisan fungsi positif $\left\{\delta_{n}\right\}$ dengan $\delta_{1}(\xi)=\delta_{1}^{\prime}(\xi)$ dan

$$
\delta_{n}(\xi)=\min \left\{\delta_{n-1}(\xi), \delta_{n}^{\prime}(\xi)\right\}, n=2,3,4, \ldots
$$

Ambil sebarang bilangan asli $m$ dan $n$ dengan $m>n$, terdapat

partisi- $\delta_{n} D_{n}=\{[u, v] ; \xi\}$ dan

partisi- $\delta_{m} D_{m}=\{[u, v] ; \xi\}$,

berdasarkan (a) maka $\delta_{m}<\delta_{n}$, yang berarti partisi$\delta_{m}$ lebih halus dari partisi- $\delta_{n}$.

Sehingga dipenuhi

$$
\begin{aligned}
\left|S_{n}-S_{m}\right|=\mid\left(D_{n}\right) \sum & f(\xi)(v-u) \\
& -\left(D_{m}\right) \sum f(\xi)(v-u) \mid<\varepsilon_{n}
\end{aligned}
$$

Karena $\varepsilon_{n} \rightarrow 0$, berarti $\left\{S_{n}\right\}$ merupakan barisan Cauchy. Karena $S_{n}$ merupakan bilangan riil, berarti barisan $\left\{S_{n}\right\}$ konvergen. Misalkan $S_{n} \rightarrow S$, maka untuk setiap $\varepsilon>0$ terdapat bilangan asli $N_{1}$ sehingga untuk setiap $n \geq N_{1}$ berlaku

$$
\left|S_{n}-S\right|<\frac{\varepsilon}{2}
$$

dan untuk setiap $\varepsilon>0$ di atas terdapat bilangan asli $N_{2}$ sehingga untuk setiap $n \geq N_{2}$ dipenuhi

$$
\varepsilon_{n}<\frac{\varepsilon}{2}
$$

Ambil $N=\operatorname{maks}\left\{N_{1}, N_{2}\right\}$. 
Ambil $\delta<\delta_{N}$, dan partisi- $\delta D=\{[u, v] ; \xi\}$ pada $[a, b]$ yang lebih halus dari partisi- $\delta_{N_{1}}$ ataupun partisi- $\delta_{N_{2}}$.

Sehingga untuk sebarang partisi- $\delta D=\{[u, v] ; \xi\}$ pada $[a, b]$ berlaku

$$
\begin{aligned}
& \left|(D) \sum f(\xi)(v-u)-S\right| \\
= & \mid(D) \sum f(\xi)(v-u)-\left(D_{N}\right) \sum f(\xi)(v-u) \\
& +\left(D_{N}\right) \sum f(\xi)(v-u)-S \mid \\
\leq & \left|(D) \sum f(\xi)(v-u)-\left(D_{N}\right) \sum f(\xi)(v-u)\right| \\
& \left.<\varepsilon_{n}+\left|S_{n}-S\right|+\mid D_{N}\right) \sum f(\xi)(v-u)-S \mid \\
< & \frac{\varepsilon}{2}+\frac{\varepsilon}{2}=\varepsilon
\end{aligned}
$$

Jadi terbukti $f$ terintegral Henstock ke $S$ pada $[a, b]$.

Selanjutnya teorema-teorema di bawah ini menunjukkan berlakunya sifat-sifat umum integral pada integral Henstock. Seperti halnya berlaku pada integral Riemann, teorema berikut ini berlaku juga pada integral Henstock.

\section{Teorema 11}

Jika fungsi $f$ terintegral Henstock pada $[a, c]$ dan pada $[c, b]$, dengan $a<c<b$, maka $f$ juga terintegral Henstock pada $[a, b]$ dan berlaku

$$
(H) \int_{a}^{b} f(x) d x=(H) \int_{a}^{c} f(x) d x+(H) \int_{c}^{b} f(x) d x
$$

\section{Bukti.}

Misalkan $(H) \int_{a}^{c} f(x) d x=A$ dan $(H) \int_{c}^{b} f(x) d x=B$.

Diberikan sebarang $\varepsilon>0$.

Terdapat fungsi positif $\delta_{1}:[a, c] \rightarrow \mathbb{R}$ sehingga untuk setiap partisi- $\delta_{1} D_{1}=\{[u, v] ; \xi\}$ pada $[a, c]$ berlaku

$$
\left|\left(D_{1}\right) \sum f(\xi)(v-u)-A\right|<\frac{\varepsilon}{2}
$$

Terdapat fungsi positif $\delta_{2}:[c, b] \rightarrow \mathbb{R}$ sehingga untuk setiap partisi- $\delta_{2} D_{2}=\{[u, v] ; \xi\}$ pada $[c, b]$ berlaku

$$
\left|\left(D_{2}\right) \sum f(\xi)(v-u)-B\right|<\frac{\varepsilon}{2}
$$

Didefinisikan fungsi positif $\delta:[a, b] \rightarrow \mathbb{R}$ dengan

$$
\delta(\xi)= \begin{cases}\min \left\{\delta_{1}(\xi), c-\xi\right\}, & \text { jika } \xi \in[a, c) \\ \min \left\{\delta_{1}(c), \delta_{2}(c)\right\}, & \text { jika } \xi \in c \\ \min \left\{\delta_{2}(\xi), \xi-c\right\}, & \text { jika } \xi \in(c, b]\end{cases}
$$

Ambil sebarang partisi- $\delta D=\{[u, v] ; \xi\}$ pada $[a, b]$.

Kemungkinan yang terjadi:

(i). $c$ merupakan salah satu titik partisi.

Maka

(ii). $c$ bukan merupakan salah satu titik partisi.

(i). Jika $c$ merupakan salah satu titik partisi.

Ambil partisi- $\delta D=\{[u, v] ; \xi\}$ pada $[a, b]$ sehingga $c$ merupakan salah satu titik partisi.

Jika $D^{\prime}=\{[u, v] ; \xi\}$ merupakan subpartisi- $\delta$ dari

$D=\{[u, v] ; \xi\}$ pada $[a, c]$ dan $D^{\prime \prime}=\{[u, v] ; \xi\}$

merupakan subpartisi- $\delta$ dari $D=\{[u, v] ; \xi\}$ pada $[c, b]$ maka $D^{\prime}$ merupakan partisi- $\delta_{1}$ dan $D^{\prime \prime}$ merupakan subpartisi- $\delta_{2}$.

(ii). Jika $c$ bukan merupakan salah satu titik partisi, maka terdapat $\{[u, v] ; \xi\}$ sehingga $c \in[u, v]$.

Kemudian kita buat partisi- $\delta D^{*}$ yang memuat

$$
([u, c], \xi) \text { dan }([c, v], c) \text { jika } u \leq \xi<c<v
$$

atau

$$
([u, c], c) \text { dan }([c, v], \xi) \text { jika } u<c<\xi \leq v
$$

Dengan demikian partisi- $\delta D^{*}=\{[u, v] ; \xi\}$ pada $[a, b]$ merupakan penghalusan partisi- $\delta$ $D=\{[u, v] ; \xi\}$.

Sehingga diperoleh

$$
\begin{aligned}
& \left|(D) \sum f(\xi)(v-u)-(A+B)\right| \\
& \leq \mid\left(D_{1}\right) \sum f(\xi)(v-u) \\
& \quad+\left(D_{2}\right) \sum f(\xi)(v-u)-A-B \mid \\
& \leq\left|\left(D_{1}\right) \sum f(\xi)(v-u)-A\right| \\
& \quad+\left|\left(D_{2}\right) \sum f(\xi)(v-u)-B\right| \\
& <\frac{\varepsilon}{2}+\frac{\varepsilon}{2}=\varepsilon \quad
\end{aligned}
$$

Jadi fungsi $f$ terintegral Henstock ke $A+B$ pada $[a, b]$, dan berlaku

$(H) \int_{a}^{b} f(x) d x=(H) \int_{a}^{c} f(x) d x+(H) \int_{c}^{b} f(x) d x$

Terbukti

Dengan adanya Teorema 11 di atas maka untuk menentukan bahwa suatu fungsi terintegral Henstock atau tidak pada $[a, b]$ dapat diperlihatkan melalui keterintegralan fungsi tersebut pada interval-interval 
bagian yang banyaknya berhingga dalam $[a, b]$ yang tidak saling tumpang tindih sehingga gabungannya sama dengan $[a, b]$.

\section{Teorema 12}

Jika $f:[a, b] \rightarrow \overline{\mathbb{R}}$ terintegral Henstock pada $[a, b]$ maka $f$ juga terintegral Henstock pada setiap selang bagian $[c, d] \subset[a, b]$.

\section{Bukti}

Diberikan sebarang $\varepsilon>0$. Menurut Lemma 10, dapat dipilih fungsi positif $\delta:[a, b] \rightarrow \mathbb{R}$, sehingga untuk setiap partisi- $\delta \quad D=\{[u, v] ; \xi\} \quad$ dan $\quad D^{\prime}=\left\{\left[u^{\prime}, v^{\prime}\right] ; \xi^{\prime}\right\} \quad$ pada $[a, b]$ berlaku

$$
\left|(D) \sum f(\xi)(v-u)-\left(D^{\prime}\right) \sum f\left(\xi^{\prime}\right)\left(v^{\prime}-u^{\prime}\right)\right|<\varepsilon
$$

Ambil sebarang partisi- $\delta D_{1}$ dan $D_{2}$ pada $[c, d]$ masingmasing dengan jumlah Riemann $S_{1}$ dan $S_{2}$.

Ambil juga partisi- $\delta D_{3}$ pada $[a, c] \cup[d, b]$ dengan jumlah Riemann $S_{3}$.

Diperoleh $P=D_{1} \cup D_{3}$ dan $\quad P^{\prime}=D_{2} \cup D_{3}$ merupakan partisi- $\delta$ pada $[a, b]$, masing-masing dengan jumlah Riemann $S_{1}+S_{3}$ dan $S_{2}+S_{3}$.

Diperoleh

$$
\begin{aligned}
\mid\left(D_{1}\right) & \sum f(\xi)(v-u)-\left(D_{2}\right) \sum f(\xi)(v-u) \mid \\
= & \left|S_{1}-S_{2}\right| \\
= & \left|S_{1}+S_{3}-S_{3}-S_{2}\right| \\
& =\left|\left(S_{1}+S_{3}\right)-\left(S_{2}+S_{3}\right)\right| \\
& =\left|(P) \sum f(\xi)(v-u)-\left(P^{\prime}\right) \sum f(\xi)(v-u)\right| \\
& <\varepsilon
\end{aligned}
$$

Menurut Lemma 10, $f$ terintegral Henstock pada $[c, d]$

\section{Teorema 13}

Jika $f(x)=0$ hampir dimana-mana pada $[a, b]$, maka $f$ terintegral Henstock pada $[a, b]$ dan $(H) \int_{a}^{b} f(x) d x=0$.

\section{Bukti}

Diketahui $f(x)=0$ hampir dimana-mana pada $[a, b]$, berarti terdapat $X \subset[a, b]$ dengan $\mu(X)=0$ sehingga

Selanjutnya didefinisikan

$$
f(x)\left\{\begin{array}{l}
=0, \text { Jika } x \notin X \\
\neq 0, \text { Jika } x \in X
\end{array}\right.
$$

$$
X_{i}=\{x \in[a, b]|i-1<| f(x) \mid \leq i\}, \quad i=1,2, \ldots
$$

sehingga $\mu\left(X_{i}\right)=0$, sehingga berlaku $X=\bigcup_{i=1}^{\infty} X_{i}$.

Untuk setiap $\varepsilon>0$ dan setiap $i$, terdapat barisan selang terbuka $\left\{I_{i j}\right\}$ sehingga $X_{i} \subset \bigcup_{j} I_{i j}$ dengan

$$
\mu\left(I_{i j}\right)<\varepsilon 2^{-(i+j)} i^{-1}
$$

Didefinisikan $\delta(\xi)>0$ pada $[a, b]$ sehingga:

(i). $(\xi-\delta(\xi), \xi+\delta(\xi)) \subset I_{i j}$, jika $\xi \in X_{i}, i=1,2, \ldots$

(ii). $\delta(\xi)$ diambil sebarang, jika $\xi \notin X_{i}, i=1,2, \ldots$

Jika $D=\{[u, v] ; \xi\}$ sebarang partisi- $\delta$ pada $[a, b]$ maka diperoleh

$$
\begin{aligned}
\left|(D) \sum f(\xi)(v-u)\right| & \leq\left|\sum_{\xi \in X} f(\xi)(v-u)\right| \\
& \leq \sum_{i=1}^{\infty} i \varepsilon 2^{-(i+j)} i^{-1} \\
& \leq \varepsilon
\end{aligned}
$$

Terbukti $f$ terintegral Henstock pada $[a, b]$ dan $(H) \int_{a}^{b} f(x) d x=0$

Teorema 13 tersebut merupakan kejadian khusus pada integral Henstock yang tidak berlaku pada integral Riemann. Selanjutnya berdasarkan Teorema 13 diperoleh akibat berikut.

\section{Akibat 14}

Jika $f$ terintegral Henstock pada $[a, b]$ dan $g(x)=f(x)$ hampir dimana-mana pada $[a, b]$ maka $g$ terintegral Henstock pada $[a, b]$ dan

$$
(H) \int_{a}^{b} g(x) d x=(H) \int_{a}^{b} f(x) d x
$$

\section{Bukti}

Misal fungsi $h=g-f$, diperoleh $h(x)=0$ hampir dimanamana pada $[a, b]$, menurut Teorema 13 di atas maka $h$ terintegral Henstock pada $[a, b]$ dan $(H) \int_{a}^{b} h(x) d x=0$.

Karena $h$ dan $f$ terintegral Henstock pada $[a, b]$, dan $g=h+f$, berdasarkan Teorema 9, diperoleh $g$ terintegral Henstock pada $[a, b]$ dan

$$
\begin{aligned}
(H) \int_{a}^{b} g(x) d x & =(H) \int_{a}^{b} h(x) d x+(H) \int_{a}^{b} f(x) d x \\
& =0+(H) \int_{a}^{b} f(x) d x
\end{aligned}
$$




$$
=(H) \int_{a}^{b} f(x) d x
$$

Berikut ini merupakan teorema yang digeneralisasi dari sifat yang berlaku pada integral Riemann.

\section{Teorema 15}

Jika $f$ dan $g$ masing-masing terintegral Henstock pada $[a, b]$ dan jika $f(x) \leq g(x)$ hampir untuk semua $x \in[a, b]$ maka

$$
(H) \int_{a}^{b} f(x) d x \leq(H) \int_{a}^{b} g(x) d x
$$

\section{Bukti}

Dengan tidak mengurangi keumuman dapat dianggap $f(x) \leq g(x)$ untuk setiap $x \in[a, b]$.

Ambil sebarang $\varepsilon>0$. Terdapat fungsi $\delta_{1}(\xi)>0$ pada $[a, b]$ sehingga untuk setiap partisi- $\delta_{1} D_{1}=\{[u, v] ; \xi\}$ pada $[a, b]$ berlaku

$$
\left|\left(D_{1}\right) \sum f(\xi)(v-u)-(H) \int_{a}^{b} f(x) d x\right| \leq \frac{\varepsilon}{2}
$$

dan terdapat fungsi $\delta_{2}(\xi)>0$ pada $[a, b]$ sehingga untuk setiap partisi- $\delta_{2} D_{2}=\{[u, v] ; \xi\}$ pada $[a, b]$ berlaku

$$
\left|\left(D_{2}\right) \sum g(\xi)(v-u)-(H) \int_{a}^{b} g(x) d x\right| \leq \frac{\varepsilon}{2}
$$

Definisikan fungsi $\delta:[a, b] \rightarrow \mathbb{R}$ dengan

$$
\delta(\xi)=\min \left\{\delta_{1}(\xi), \delta_{2}(\xi)\right\}
$$

Menurut Teorema 6 , jika $D=\{[u, v] ; \xi\}$ partisi- $\delta$ pada $[a, b]$, maka $D$ juga merupakan partisi- $\delta_{1}$ dan partisi- $\delta_{2}$ $\operatorname{pada}[a, b]$.

Jadi untuk sebarang partisi- $\delta D=\{[u, v] ; \xi\}$ pada $[a, b]$ berlaku

$$
\left|(D) \sum f(\xi)(v-u)-(H) \int_{a}^{b} f(x) d x\right| \leq \frac{\varepsilon}{2}
$$

dan

$$
\left|(D) \sum g(\xi)(v-u)-(H) \int_{a}^{b} g(x) d x\right| \leq \frac{\varepsilon}{2}
$$

sehingga

$$
\begin{aligned}
(H) \int_{a}^{b} f(x) d x-\frac{\varepsilon}{2} & \leq(D) \sum f(\xi)(v-u) \\
& \leq(D) \sum g(\xi)(v-u)
\end{aligned}
$$

$$
\leq \frac{\varepsilon}{2}+(H) \int_{a}^{b} g(x) d x
$$

diperoleh

$$
(H) \int_{a}^{b} f(x) d x \leq(H) \int_{a}^{b} g(x) d x+\varepsilon
$$

Karena sebarang $\varepsilon>0$, maka

$$
(H) \int_{a}^{b} f(x) d x \leq(H) \int_{a}^{b} g(x) d x
$$

Misalkan fungsi $f:[a, b] \rightarrow \overline{\mathbb{R}}$ terintegral Henstock pada $[a, b]$. Berdasarkan Teorema 12, untuk setiap $x \in$ $[a, b]$ fungsi $f$ juga terintegral Henstock pada $[a, x] \subset[a, b]$. Sehingga dapat didefinisikan fungsi $F:[a, b] \rightarrow \mathbb{R}$ dengan

$$
F(x)=(H) \int_{a}^{x} f(t) d t, a \leq x \leq b,
$$

dan selanjutnya $F$ disebut fungsi primitif Henstock fungsi $f$ pada $[a, b]$. Dengan demikian definisi integral Henstock dapat pula ditulis sebagai berikut.

\section{Definisi 16}

Fungsi terukur $f$ dikatakan terintegral Henstock pada $[a, b]$ jika ada fungsi $F:[a, b] \rightarrow \mathbb{R}$ sehingga untuk setiap $\varepsilon>0$ terdapat fungsi positif $\delta, \delta:[a, b] \rightarrow \mathbb{R}$ sehingga untuk setiap partisi- $\delta D=\{[u, v] ; \xi\}$ pada $[a, b]$ berlaku

$$
\begin{aligned}
& \mid(D) \sum f(\xi)(v-u)-F(a, b) \mid \\
&=\left|(D) \sum f(\xi)(v-u)-F(u, v)\right| \\
&<\varepsilon
\end{aligned}
$$$$
\text { dengan } F(u, v)=F(v)-F(u) \text {. }
$$

Teorema berikut ini merupakan sebuah sifat dari integral Henstock yang sering disebut sebagai Lemma Henstock.

\section{Teorema 17 (Lemma Henstock)}

Jika fungsi $f$ terintegral Henstock pada $[a, b]$, yaitu terdapat fungsi $F:[a, b] \rightarrow \mathbb{R}$ sehingga untuk setiap $\varepsilon>0$ terdapat fungsi positif $\delta, \delta:[a, b] \rightarrow \mathbb{R}$ sehingga untuk setiap partisi- $\delta D=\{[u, v] ; \xi\}$ pada $[a, b]$ berlaku

$$
\left|(D) \sum f(\xi)(v-u)-F(u, v)\right|<\varepsilon
$$

maka untuk setiap partisi bagian $D_{1}$ dari $D$ berlaku

$$
\left|\left(D_{1}\right) \sum f(\xi)(v-u)-F(u, v)\right|<2 \varepsilon
$$




\section{Bukti}

Ambil sebarang partisi- $\delta D=\{[u, v] ; \xi\}$ pada $[a, b]$.

Ambil $D_{1}$ sebarang subpartisi- $\delta$ dari $D$, sebut :

$$
\begin{aligned}
& J_{i}=\left[u_{i}, v_{i}\right] \text { jika }\left(\left[u_{i}, v_{i}\right] ; \xi_{i}\right) \in D_{1} \\
& I_{k}=\left[u_{k}, v_{k}\right] \text { jika }\left(\left[u_{k}, v_{k}\right] ; \xi_{k}\right) \in D-D_{1}
\end{aligned}
$$

Karena $f$ terintegral Henstock pada $[a, b]$ dan $I_{k} \subset[a, b]$ untuk setiap $k$, menurut Teorema $11, f$ terintegral Henstock pada $I_{k}$ untuk setiap $k$.

Sehingga untuk setiap $\varepsilon>0$ terdapat fungsi positif $\delta_{k}$, $\delta_{k}:[a, b] \rightarrow \mathbb{R}$ sehingga untuk setiap partisi- $\delta_{k}$

$D_{k}=\{[u, v] ; \xi\}$ pada $I_{k}$ berlaku

$$
\left|\left(D_{k}\right) \sum f(\xi)(v-u)-F(u, v)\right|<2^{-k} \varepsilon
$$

Jadi $D=D_{1} \bigcup\left(\bigcup_{k} D_{k}\right)$.

Diperoleh

$$
\begin{aligned}
& \left|\left(D_{1}\right) \sum f(\xi)(v-u)-F(u, v)\right| \\
& =\mid(D) \sum f(\xi)(v-u)-F(u, v) \\
& \quad-\sum_{k}\left(D_{k}\right) \sum f(\xi)(v-u)-F(u, v) \mid \\
& \leq \mid(D) \sum f(\xi)(v-u)-F(u, v) \\
& \quad+\sum_{k}\left(D_{k}\right) \sum f(\xi)(v-u)-F(u, v) \mid \\
& <\varepsilon+\sum_{k} \varepsilon 2^{-k} \\
& \leq 2 \varepsilon
\end{aligned}
$$

\section{KESIMPULAN}

Dari uraian ini dapat disimpulkan bahwa:

Pendefinisian integral Henstock didasarkan atas partisi- $\delta$, dimana partisi tersebut merupakan sebuah fungsi positif $\delta(x)>0$ untuk setiap $x \in[a, b]$. Partisipasi diperoleh dengan menggantikan konstanta positif $\delta$ pada konstruksi integral Riemann.

Sifat-sifat dasar yang berlaku pada integral Riemann berlaku pada integral Henstock, yang mana sifat-sifat dasar integral Henstock lebih konstruktif.

\section{DAFTAR PUSTAKA}

Bartle, R. G. \& Sherbert, D. R., (1994), Introduction to Real Analysis, Second Edition, John Wiley \& Sons. Inc, New York.

Gordon, R. A., (1994), The Integrals of Lebesgue, Denjoy, Perron, and Henstock, Graduate Studies in Mathematics 4, American Mathematical Society, Providence.

Guoju, Y. \& Tianqing, A., (1998), On Henstock-Dunford and Henstock Pettis Integral, 12 hlm, Hindawi Publishing Corp, http://ijmms.hindawi.com. 08 Januari 2005, Pk. 17.00 WIT

Lee, P. Y., (1989), Lanzhou Lectures on Henstock Integration, Series in Real Analysis vol. 2, World Scientific, Singapore.

Royden, H. L., (1987), Real Analysis, Third Edition, Macmillan Publishing Company, New York.

Rudin, W., (1976), Principles of Mathematical Analysis, Third Edition, Mc Graw-Hill Kogakusha. Ltd, Tokyo.

Schecter, E. (2001). An Introduction to The Gauge Integral. $10 \mathrm{hlm}$. http://www.math.vanderbilt.edu/ $\sim$ schectex/ccc/. 08 Januari 2005, pk. 18.47 WIT.

Sinay, L. J. (2005) , Integral Henstock dan Sifat-Sifatnya, Skripsi S1 pada Jurusan Matematika FMIPA Universitas Pattimura, Ambon.

Soemantri, R., (1988), Analisis Real I, Penerbit Karunika, Universitas Terbuka, Jakarta.

Thobirin, A. (1997). Beberapa Integral Jenis Riemann. Tesis Magister pada Jurusan Matematika FMIPA Universitas Gadjah Mada, Yogyakarta. 
Barekeng Vol. 6 No. 2 